\title{
The search for symmetry: 25 years in review
}

\author{
KAREN M. LIONELLO-DENOLF \\ University of Massachusetts Medical School, Shriver Center, Waltham, Massachusetts
}

\begin{abstract}
It has been 25 years since the publication of Sidman et al.'s (1982) report on the search for symmetry in nonhuman animals. They attributed their nonhuman subjects' failure to the absence of some critical experiences (e.g., exemplar training, control of location variables, and generalized identity matching). Since then, species ranging from rats to chimpanzees have been tested on symmetry, and the results have been equivocal. Twenty-four investigations of symmetry in nonhumans are reviewed to determine whether the underlying factors first addressed by Sidman et al. (1982) have been verified and whether new factors have been identified. The emergent picture shows that the standard procedures as typically implemented on a three-key apparatus are insufficient by themselves to produce emergent symmetry in nonhumans. Recent successful demonstrations of symmetry in sea lions and pigeons have clarified certain important stimulus control variables (i.e., select and reject control) and suggest avenues for future research. Reliable symmetry may be achievable with nonhumans if training and test procedures that encourage compatible stimulus-control topographies and relations are designed.
\end{abstract}

It has been more than 25 years since the publication of Sidman et al.'s (1982) chronicle of the search for symmetry - the finding that after learning to match samples to comparisons in a conditional discrimination, subjects will match the same stimuli when their respective functional roles are reversed-in nonhuman animals. That article and its companion, Sidman and Tailby (1982), have generated considerable interest in the phenomenon of stimulus equivalence and have stimulated much follow-up research with college students, young children, and individuals with intellectual disabilities, some of whom exhibited minimal language skills. Furthermore, a range of nonhuman animals, including chimpanzees, monkeys, sea lions, dolphins, rats, and pigeons have been tested for symmetry, as well as the other defining properties of stimulus equivalence. There has been substantial variability in the data resulting from these investigations, particularly those concerning nonhuman animals. Despite our having reached the quarter-century mark since Sidman et al.'s (1982) landmark article, no one has since reviewed the literature concerning nonhumans, and, thus, it seems opportune to do so.

In the present review of published studies on symmetry in nonhumans from 1982 through 2007, the goals are to summarize this research area and to assess progress made in this 25 -year period. The review begins with a brief summary of the history of the problem before 1982. Next, Sidman et al.'s (1982) studies with monkeys, baboons, and children are described, followed by an examination of how the issue of symmetry fits within the larger domain of stimulus equivalence, as well as a definition of the research problem and of certain relevant theoretical considerations. The review concludes with a summary of the extant empirical investigations in order to assess progress, both conceptual and methodological, and to identify questions and issues that require further study.

\section{BACKWARD ASSOCIATIONS}

\section{Studies With Humans}

Interest in symmetrical associations is not limited to the stimulus equivalence literature. Prior to 1982, there was longstanding interest in the problem of so-called backward associations. As early as 1885, for example, Ebbinghaus $(1885 / 1913)$ reported savings in humans' backward recall of a list of nonsense syllables $24 \mathrm{~h}$ after learning the list in the forward direction.

In paired-associate learning, Asch and Ebenholtz (1962) proposed that once a forward association was established, a backward relation of equal strength was also formed. They conducted several studies showing this to be the case, although their demonstrations did not involve conditional discriminations of the sort used in contemporary equivalence studies. Moreover, they believed that the asymmetry sometimes found in paired-associate research (e.g., Bartling \& Thompson, 1977; Coutu, 1966; Levy \& Nevill, 1974; Lockhart, 1969; Wollen, Fox, \& Lowry, 1970) was due to differential availability of the items for recall, independent of the strength of forward or backward associations. Their work showed that backward and forward associations do indeed form in equal strength when item availability is equal. Much additional evidence for backward associations in paired associates also exists (Kahana, 2002; Mandler, Rabinowitz, \& Simon, 1981; Murdock, 1962, 1966; Tedford \& Hazel, 1973).

K. M. Lionello-DeNolf, karen.lionello-denolf@umassmed.edu 


\section{Studies With Nonhumans}

In early investigations with nonhumans, researchers trained rats to run various types of mazes and then tested the rats' ability to run the maze in the opposite direction. Accurate running of the maze in the backward direction was taken as evidence of backward associations (e.g., Bunch \& Lund, 1932; H. A. Carr \& Freeman, 1919; Dorcas, 1932). Although these studies reported only variable success, interest in backward associations did not wane as the years passed, and the phenomenon was studied in different ways.

Within the classical conditioning tradition, interest in backward associations can be traced to Pavlov (1928). In his preparation, an unconditioned stimulus (US), such as food or a shock, is presented prior to the presentation of a conditioned stimulus (CS), such as a tone or light. Evidence for backward associations is provided if a conditioned response (CR) develops when the CS is presented. Pavlov's initial findings indicated that CRs develop in backward conditioning when only a few training trials are presented but that the CRs tend to disappear with extended training.

Whether or not backward associations develop as a result of backward conditioning procedures has been controversial. Some researchers have found evidence for conditioned inhibition, rather than the development of CRs, after backward conditioning (Delamater, LoLordo, \& Sosa, 2003; Moscovitch \& LoLordo, 1968; Siegel \& Domjan, 1971; Tait \& Saladin, 1986). For instance, Moscovitch and LoLordo showed that after repeated backward US-CS pairings, the CS suppressed avoidance behavior when compared with another CS with a history of uncorrelated pairings with the US. Siegel and Domjan showed that backward pairings led to the retardation of conditioned responding when the CS was later used in training with forward CS-US pairings.

Other researchers, however, have provided evidence for an excitatory association after backward US-CS pairings (Arcediano, Escobar, \& Miller, 2003; Barnet \& Miller, 1996; Hearst, 1989; Keith-Lucas \& Guttman, 1975; Wagner \& Terry, 1975; see Razran, 1956, and Spetch, Wilkie, \& Pinel, 1981, for reviews). For example, Hearst trained pigeons on a task in which a stimulus, CS1, was followed by food on half of the trials and by only a lighted food hopper (i.e., no food) on the remaining trials. For some pigeons, a second stimulus, CS2, followed all food presentations, but, for other pigeons, the CS2 followed all no-food presentations. Hearst noted that few pecks occurred to the CS2 during training (i.e., CRs did not develop). However, in a subsequent test in which the CS2 was followed by food on half of the trials and by no food on the other half, Hearst found that the former pigeons pecked more to CS2 than did the latter pigeons and that the responding of control pigeons (trained without the CS2 or with the CS2 uncorrelated with US presentations) fell between these two.

Researchers in the operant conditioning literature were also interested in the existence of backward associations in animals (e.g., Gray, 1966; Hogan \& Zentall, 1977; Holmes, 1979; Rodewald, 1974; see also Kendall, 1983), and their studies directly anticipated Sidman et al.'s (1982) research interests. The earliest investigations (Gray, 1966; Hogan \& Zentall, 1977; Holmes, 1979; Rodewald, 1974) involved pigeon subjects that were trained to match hue or line samples to hue, line, or shape comparisons in a standard three-response-key pigeon chamber. Once the matching tasks were learned to varying levels of accuracy $(75 \%-90 \%$ correct $)$, the roles of the samples and comparisons were reversed. In these studies, the sample stimuli were always presented in a central location, and the comparisons were always presented in side locations. In two studies (Gray, 1966; Rodewald, 1974), the pigeons were trained to intermediate accuracy levels, and, in Gray, testing was done in extinction. In one study, pigeons were given extensive training on identity matching and were then switched to arbitrary matching prior to test (Holmes, 1979). A backward association or symmetry test consisted of presenting former comparisons as samples (now in the central location for the first time) followed by a choice between former samples as comparisons (now in the side locations for the first time). Evidence for symmetry in these studies was poor: Accuracy was at chance levels (Gray, 1966; Rodewald, 1974) or at a level comparable to that of initial performance on new relations (Holmes, 1979).

Hogan and Zentall (1977) conducted a study in which baseline relations were trained to high accuracy levels, test-trial performance was reinforced, and a control group to account for possible effects of rapid learning during test sessions was included. Pigeons were divided into consistent and inconsistent test groups. During reinforced symmetry test sessions, choices consistent with symmetry (e.g., pecking a vertical comparison after a red sample when the subject had been trained to peck a red comparison after a vertical sample) were reinforced for the consistent group, but, for the inconsistent group, choices inconsistent with symmetry were reinforced (e.g., pecking a horizontal target after a red sample, given the same training as above). Strong evidence for symmetry would be indicated by accuracy well above chance in the consistent group and well below chance in the inconsistent group on the first test session. Weaker evidence would be indicated by faster acquisition of the symmetrical relation in the consistent group relative to the inconsistent group over repeated reinforced test sessions. However, Hogan and Zentall's results showed that first-test-session accuracies were at chance for both groups and that the consistent group did not learn the symmetry task any faster than the inconsistent group did. This was true after training on both simultaneous and zero-delay matching-to-sample.

Prior to Sidman et al.'s (1982) report on symmetry, there had been no systematic investigation of backward associations in nonhuman primates (but see Weinstein, 1945). However, there was in the literature a general interest in inferring linguistic and other higher order processes from the matching-to-sample procedure. Furthermore, SavageRumbaugh, Rumbaugh, Smith, and Lawson (1980) published an account of a teaching program for 2 chimpanzees in which the subjects were taught to sort items by category (food or tools) and to label each of the individual items with different lexigrams (i.e., arbitrary forms). Both chimps later matched the individual lexigrams to the TOOL 
and FOOD category lexigrams, even though this behavior was not explicitly taught. These data suggested the possibility of stimulus equivalence in nonhuman primates.

\section{STIMULUS EQUIVALENCE AND THE SEARCH FOR SYMMETRY}

Sidman et al. (1982) published their report concurrently with another report, which offered a new operational definition of stimulus equivalence derived from mathematical logic (Sidman \& Tailby, 1982). These two articles followed more than a decade of research concerning reading comprehension in individuals with intellectual disabilities, in which stimulus equivalence had been the central focus. In that work, Sidman and colleagues demonstrated that individuals who lacked basic reading comprehension could be taught a few conditional relations, via auditory-visual (e.g., they would hear "apple" and choose a picture of an apple from among two or more alternatives) and visualvisual (e.g., they would see the printed word apple and choose a picture of an apple) matching-to-sample procedures. Thereafter, new relations involving dictated words, printed words, and pictures emerged without further training (e.g., Sidman, Cresson, \& Willson-Morris, 1974). Similar emergent relations involving a variety of stimulus types have been demonstrated in humans displaying a wide range of intellectual and language abilities (Eikeseth \& Smith, 1992; Fields, Adams, Brown, \& Verhave, 1993; Sidman et al., 1982; Spradlin, Cotter, \& Baxley, 1973).

Sidman and Tailby (1982) defined stimulus equivalence in terms of three relational properties: reflexivity, symmetry, and transitivity. Reflexivity is shown when an individual matches a stimulus to itself without explicit training on that identity relation. Symmetry entails a bidirectional relationship between two stimuli. For instance, if an individual is taught to match a red sample stimulus to a vertical line comparison stimulus (AB), symmetry is shown if he or she subsequently matches a vertical line sample to a red comparison (BA) without further training. Finally, transitivity entails a relation among stimuli across two (or more) trained relations. It would be demonstrated, for example, if after training to match a red sample to a vertical line $(\mathrm{AB})$ and a vertical line to a triangle $(\mathrm{BC})$, an individual spontaneously matches a red sample to a triangle (AC). A test for the emergence of a $\mathrm{CA}$ relation after $\mathrm{A}-\mathrm{B}$ and $\mathrm{B}-\mathrm{C}$ training has been termed a combined test for all three relational properties of equivalence, because such emergence logically requires those properties (see Sidman, 1994, for detailed consideration of the reasoning behind this assertion).

Another aspect of the Sidman et al. (1982) article was to consider the terminology used to describe the nature of learning in certain conditional discrimination procedures. When matching-to-sample is used to describe the behavior of an individual rather than a type of procedure, they argued, the term matching seems to imply that an equivalence relation has been established; the related stimuli go together. In this context, the authors argued for a strong distinction between matching-to-sample as the name of an experimental procedure and matching-to-sample as a descriptor of behavior. It is easy to see how the distinction could become blurred, particularly when identity relations are trained: When red samples are matched to red comparisons, it may appear that the subject has learned to "match same (or equivalent)." Sidman et al. (1982) argued, however, that such matching need entail neither sameness nor equivalence; it may be merely a rote (i.e., "if ... then") conditional discrimination. Their arguments were supported subsequently by a number of studies with nonhuman subjects (Iversen, 1997; Iversen, Sidman, \& Carrigan, 1986; Lionello \& Urcuioli, 1998).

The main purposes of Sidman et al.'s (1982) article were (1) to drive home the distinction between true matching (the stimuli bear a relation of sameness) and rote conditional discrimination (stimuli are related by "if . . . then" rules) in matching-to-sample procedures and (2) to contrast the performances of nonhuman primates (monkeys and baboons) with human preschool children on symmetry procedures. A majority of the children tested exhibited symmetry with very minimal training. The nonhuman primates, by contrast, failed to exhibit symmetry, despite a variety of procedure variations that were designed to enhance performance. These variations addressed variables potentially related to symmetry that had not been considered in earlier work with pigeons (e.g., Hogan \& Zentall, 1977; Holmes, 1979; Rodewald, 1974).

\section{Methodological Developments}

The Sidman et al. (1982) study and its companion Sidman and Tailby (1982) were noteworthy also because they established de facto standard methodology for assessing equivalence relations. This methodology included not only the probe tests for reflexivity, symmetry, and transitivity, but also the intermixture of probe trials with baseline trials. The advantage of the intermixture procedure was that baseline relations could be evaluated concurrently with probed relations. If probes did not confirm the presence of a targeted emergent relation (e.g., symmetry), performance on baseline trials determined whether the failure was due to decrement of the prerequisite baseline relations. The symmetry study by Sidman et al. (1982) also included a procedural variation designed to establish another critical behavioral prerequisite for success: independent assessment of the subjects' abilities to make successive discriminations among all samples and simultaneous discrimination among all comparisons (cf. Saunders \& Spradlin, 1989). The variation was to directly train the subjects on the identity relations (A-A and $\mathrm{B}-\mathrm{B})$ in order to familiarize the animals with all of the stimuli in both sample and comparison positions (the issue of stimulus position has become an important focus of research and is discussed more fully in the Studies Failing to Find Evidence section, below). Finally, the probability of reinforcement on baseline trials was lowered so as to render nonreinforcement of probe trials less discriminable. The consistent failure of Sidman et al.'s (1982) monkey and baboon subjects to exhibit symmetry despite all of these precautions was deemed especially noteworthy and led directly to the publication of largely negative results in the study. 


\section{Theoretical Considerations}

The issue of symmetry in nonhumans becomes especially important when the larger context of stimulus equivalence theory is considered. One of the major points distinguishing the various theoretical accounts is the role of language. Many accounts suggest that the ability to form equivalence classes is related to demonstrable language capabilities - for example, naming theory (Horne \& Lowe, 1996) and relational frame theory (RFT) (Devany, Hayes, \& Nelson, 1986; Hayes, Barnes-Holmes, \& Roche, 2001; Hayes, Gifford, \& Wilson, 1996)_but other researchers disagree (e.g., D. Carr, Wilkinson, Blackman, \& McIlvane, 2000; Sidman, 1990, 1994, 2000).

Although proponents of both naming theory and RFT link equivalence to language ability, they differ in how they posit that the two are related. Language ability is a key component of RFT, and one interest of RFT consists in showing that derived stimulus relations, such as equivalence and verbal behavior, are the result of relational frames. RFT does not address the abilities of nonhuman animals in general or symmetry in particular. By contrast, naming proponents suggest that naming gives rise to equivalence: Stimuli evoke the same name as other stimuli, and so the same listener behavior is directed to other members of the same class. If the individual does not overtly or covertly name the sample, matching in accordance with equivalence classes will not occur. Thus, nonhumans and humans lacking language skills will not show symmetry or equivalence.

Finally, Sidman (1990) proposed that stimulus equivalence arises from naturally occurring reinforcement contingencies in the environment that create the prerequisite conditions for the defining behavioral properties of equivalence. Species will have varying potentials to form equivalence relations, and additional factors, such as testing conditions, context, and history, will determine whether and how this potential is realized. One good way to settle this debate, of course, would be to conclusively show the behavioral relations defining stimulus equivalence in a species with no language ability. There have been positive reports of reflexivity (Barros, Galvão, \& McIlvane, 2002; Herman \& Gordon, 1974; Herman, Hovancik, Gory, \& Bradshaw, 1989; Oden, Thompson, \& Premack, 1988; Peña, Pitts, \& Galizio, 2006) and transitivity (D’Amato, Salmon, Loukas, \& Tomie, 1985; Kuno, Kitadate, \& Iwamoto, 1994) in nonhumans, but the results of studies investigating symmetry have been much more equivocal, as the following review will show.

\section{SYMMETRY IN NONHUMANS}

This review will focus on empirical studies relating to symmetry in nonhuman animals investigated in matchingto-sample (i.e., conditional discrimination) contexts. The literature can be divided into three groups of studies, depending on the outcome: those that failed to find evidence of symmetry, those that found mixed evidence, and those that have found strong evidence. Table 1 summarizes the studies reviewed here and organizes them by the three aforementioned categories, as well as describing some additional characteristics.

\section{Studies Failing to Find Evidence}

Of the 24 studies considered, 11, including Sidman et al. (1982), failed to find any evidence at all of symmetry. Seven of these used pigeons as subjects, and the remaining studies used primates, such as monkeys, baboons, and chimpanzees. The earliest investigations (Gray, 1966; Hogan \& Zentall, 1977; Holmes, 1979; Rodewald, 1974) involved pigeon subjects and were discussed previously.

D'Amato et al. (1985) conducted a study using consistent and inconsistent test manipulations (similar to the test groups used by Hogan \& Zentall, 1977); their subjects were 6 monkeys, and each monkey was given both a consistent and an inconsistent test (counterbalanced across subjects). Additionally, the monkeys were trained on four conditional relations and given symmetry tests with all four. In Test 1, symmetry was tested with two of the relations, and half of the monkeys were given the consistent test first and the inconsistent test second, with a return to baseline in between. For the other half of the monkeys, the opposite was true. On Test 1, 2 of the 6 monkeys matched at $80 \%$ on the consistent test and at $20 \%-30 \%$ on the inconsistent test (where chance performance was $50 \%$ correct), suggesting symmetry. On Test 2 (with the remaining two relations), however, only 1 of those same monkeys showed the same pattern (the remaining monkeys matched at chance). Moreover, D'Amato et al. suggested that this symmetry result might have been due to stimulus generalization and not to a bidirectional relation between the stimuli, because the correct comparison in Task 2 was visually similar to the sample in Task 1 . Thus, when the Task 2 comparison became a sample in the symmetry task, control by the sample in Task 1 could have generalized to this new sample and resulted in performance that looked like symmetry. Further support for this conclusion was found in the data of a second monkey. This other monkey received training with Task 2 stimulus combinations that should have resulted in below-chance accuracy on symmetry trials if stimulus generalization was occurring, which was, in fact, what the data showed.

Sidman et al.'s (1982) study was designed to address some of the shortcomings of the pigeon studies. One possible competing source of stimulus control in earlier studies was that switching the roles of the samples and comparisons for the symmetry test caused the stimuli to appear in new locations (i.e., during training, samples were presented only on the center key, and comparisons were presented only on the side keys, but during the symmetry test, former samples were presented on side keys as comparisons, and former comparisons were presented on the center key as samples). Sidman et al. (1982) trained their monkey and baboon subjects on identity (A-A, B-B) relations (in sessions separate from those for A-B training) to provide them with experience with each stimulus in each role and in each location. In Table 1, the columns under Location Controls? indicate whether identity training or a method distinct from identity training was used 
Iable 1

Studies Investigating the Emergence of Symmetry in Nonhuman Animals

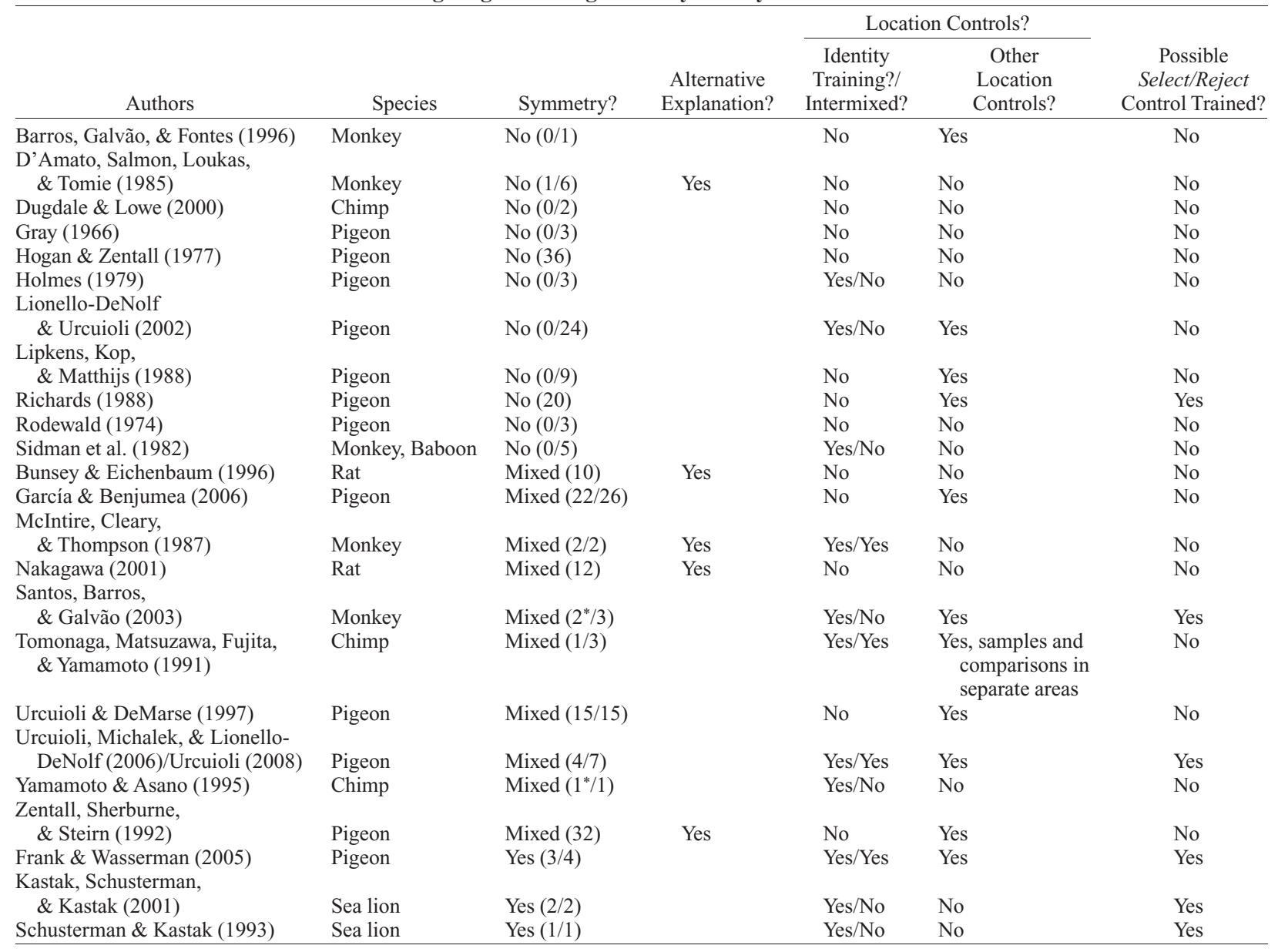

Note-The first number in the Symmetry? column indicates the number of subjects showing evidence for symmetry, and the second number shows the total number of subjects. For studies reporting group data only, only the total number of subjects is shown. *Symmetry was demonstrated and then went away.

to control for location effects. To control for the possible rapid learning of symmetrical relations due to reinforcement in test, they used a probe trial procedure in which symmetry test trials were unreinforced and inserted into a baseline session in which the overall density of reinforcement had been reduced. Finally, in one study, they also trained arbitrary relations to ensure that the subjects were able to make successive discriminations between sample stimuli. Despite all of these potentially helpful procedural additions, no subject showed symmetry (i.e., they all matched at chance).

Later research with monkey subjects went on to confirm that stimulus location is part of what is learned during matching-to-sample training. Iversen et al. (1986) showed that, when monkeys are trained on identity matching-to-sample with the samples always presented on the center key and the comparisons on the two side keys, simply moving the stimuli to new locations (e.g., samples on the left key and comparisons on the remaining two) causes accuracy to fall to chance levels. The reinforcement contingencies remained the same; the only change in the task was the locations in which the stimuli were presented. Later research showed that the same is true for rats (Iversen, 1997) and pigeons (Lionello \& Urcuioli, 1998). These studies show that animals do not learn to "match A to B." Instead, they learn something much more specific: "Match A on the center to B on the side" (i.e., location is a part of stimulus definition). These data seem to suggest that it is unlikely that animals learn general or conceptual relations between stimuli and that they instead learn stimulus-specific relations. Other data, however, suggest that this specificity of learning may be a result of the particular training procedures used. For example, Lionello-DeNolf and Urcuioli (2000) showed that when pigeons are trained on matching tasks in which the samples and comparisons appear in multiple locations during training, matching performance does transfer to novel locations. This suggests that the training or testing format itself might encourage learning of stimulusspecific relations. In other words, evidence for symmetry or other conceptual relations might be found if a different procedure is used.

Lipkens, Kop, and Matthijs (1988) trained pigeons on matching-to-sample in a response chamber in which 
two response keys were located on each of three different walls. When stimuli were presented on either of two side walls, the samples and/or comparisons were colors (when a sample was presented, it appeared with equal probability on the left and the right key of a given wall), but, when stimuli were presented on the middle wall, the samples and/or comparisons were left and right locations (when a sample was presented, one key-left or rightwas lit orange; when comparisons were presented, both keys were lit orange). Pigeons were trained to match color samples to location comparisons (i.e., A-B matching, where A samples were presented on the left wall and $B$ comparisons were presented on the middle wall) and to match location samples to color comparisons (i.e., B-C matching, where $\mathrm{B}$ samples were presented on the middle wall and $C$ comparisons were presented on the right wall). For the symmetry test (probe trials inserted into the baseline), samples and comparisons switched roles relative to baseline training, but the locations at which they appeared remained the same (i.e., B-A matching, where B samples were presented on the middle wall and $\mathrm{A}$ comparisons were presented on the left wall; $\mathrm{C}-\mathrm{B}$ matching, where $\mathrm{C}$ samples were presented on the right wall and $\mathrm{B}$ comparisons were presented on the middle wall). However, pigeons still did not show symmetry and instead matched at chance. Lipkens et al.'s analysis of error patterns during the probe test suggests that several stimulus-control topographies were present. On baseline trials during the test session, location remained a controlling variable. In addition, the pigeons had to traverse different distances when responding to samples and comparisons, depending on where the stimuli were presented. For example, when sample A1 was presented on the left key of the left side wall, there was a longer distance to reach the comparisons on the middle wall than when sample A1 was presented on the right key of the left side wall. These distances may also have become part of the functional stimulus.

Lionello-DeNolf and Urcuioli (2002) also conducted a symmetry study in which stimulus location was controlled. Pigeons were trained on matching-to-sample tasks in which the samples and comparisons were presented in multiple locations during training (cf. Lionello-DeNolf \& Urcuioli, 2000). In the testing session, pigeons were tested on the baseline relations presented in a novel location and on symmetry with the samples and comparisons presented in those same locations. In addition, pigeons were divided into consistent and inconsistent test groups and tested with reinforcement. Both groups matched at chance, however, in testing and learned B-A matching at the same rate. In a follow-up study, the pigeons were further trained on $\mathrm{A}-\mathrm{A}$ and $\mathrm{B}-\mathrm{B}$ matching and tested for reflexivity and then symmetry again. The results were again negative. Different pigeons were then trained on three separate arbitrary matching tasks: A-B, C-A, and B-D. The logic here was similar to that for training with identity relations: Such training gives pigeons experience with the A and B stimuli as both samples and comparisons and in all locations. Each relation was trained in separate sessions, and then the symmetry tests were conducted. If symmetry was not observed in the B-A test, B-A matching was trained to a high accuracy before testing for $\mathrm{A}-\mathrm{C}$ symmetry. Likewise, if symmetry was not observed, A-C matching was trained to a high accuracy before testing D-B symmetry. This training provided a history of reinforced examples of symmetry, another variable identified as important by Sidman et al. (1982). Nonetheless, all pigeons matched at chance and learned the relations at the same rate.

Barros, Galvão, and Fontes (1996) tested 1 monkey for symmetry on a matching task in which the samples and comparisons were locations. Training was conducted with a nine-key response panel. At the beginning of a trial, a sample, lit white, could appear in one of several locations. After an observing response, three comparisons, also lit white, were presented in random locations. The monkey was trained to match one location to another. For example, when Key 1 was the sample, Key 5 was the correct comparison. The locations of the incorrect comparisons varied across trials. In the symmetry test, Key 5 appeared as the sample, and Key 1 was the correct comparison. In the testing session, the monkey's choices were not based on symmetry. Rather, the monkey tended to respond in the same physical direction as it did in training. To continue the example above, if choosing comparison Key 5 after sample Key 1 in training meant responding to the left of Key 1 , in the testing session, the monkey responded to the left of Key 5 (rather than to Key 1, which was to the right of Key 5).

Finally, Richards (1988) controlled for stimulus location by training and testing for symmetry using a successive matching procedure: All stimuli were presented in a single location. For example, red and green sample presentations were followed by a vertical comparison on some trials and a horizontal comparison on others (samples and comparisons were presented for a fixed amount of time). When the sample was red, trials with a vertical comparison ended in reinforcement, and trials with a horizontal comparison ended in a blackout period. When the sample was green, trials with a vertical comparison ended in a blackout period, and trials with a horizontal comparison ended in reinforcement. The dependent measure was a discrimination ratio: More pecks to vertical than to horizontal comparisons after red samples and more pecks to horizontal than to vertical comparisons after green samples indicated that the pigeons had learned the task. In the testing session, vertical and horizontal lines were presented as samples and red and green targets were the comparisons. Despite the stimulus location's being controlled, the pigeons did not show symmetry (discrimination ratios varied around .5). Subsequent control experiments, which altered the stimulus locations in training and testing, were also unsuccessful in demonstrating symmetry.

The last of the studies that failed to find evidence of symmetry was conducted with 2 chimpanzees that had extensive training histories to respond via a lexigram-based language system (Dugdale \& Lowe, 2000). Dugdale and Lowe reasoned (1) that training multiple examples of symmetry might be required before animals show emergent 
symmetry with new relations and (2) that using animals with a lengthy history of such experience would provide the best chance of success on a symmetry test. Moreover, these were the same chimps whose prior behavior had suggested formation of equivalence classes, although the formal tests had not been conducted (Savage-Rumbaugh et al., 1980). They had extensive training to match lexigram stimuli to real-world objects and vice versa, which seemed to provide a history of multiple exemplar training on symmetrical relations. Dugdale and Lowe then trained the chimps on a matching-to-sample task with hue and form (two-dimensional) stimuli in a standard three-key apparatus. Stimulus location was not controlled. In the initial symmetry test, 1 chimp was given unreinforced symmetry probe trials inserted into the baseline, and accuracy was at chance. In subsequent test sessions, probes were reinforced, and identity trials were included. Accuracy on symmetry tests was at chance for both chimps, and baseline performances degraded to low levels, suggesting that there was a general loss of stimulus control by the experimenter-defined samples.

\section{Studies Finding Mixed Evidence}

These studies can be divided into two categories: (1) those in which symmetry was found, but in which there may be alternative explanations for the finding, and (2) those in which evidence for symmetry was found in some subjects (but not all) or in which accuracies on symmetry tests were at intermediate levels (i.e., 70\%-85\%).

Studies with possible alternative explanations. There are three such studies. The first was a study with monkeys by McIntire, Cleary, and Thompson (1987). McIntire et al. reasoned that if naming facilitated class formation with humans, teaching monkeys common names for stimuli should facilitate class formation for them as well. Monkeys were taught to make a common response (such as holding down a key continuously for $3.5 \mathrm{sec}$ ) to each member of one training class and a different response (fixed-ratio [FR] 8) to each member of the other class. For example, on trials in which Sample A1 was presented, the monkeys were required to respond to it with an FR response before the comparisons appeared. Then, when making a comparison choice, the monkeys were again required to make the FR response. In contrast, when Sample A2 was presented, a hold response was required in order to produce the comparisons, and again the hold response was required when a choice was made. Using this procedure, the monkeys were trained on both identity and arbitrary matching-to-sample. They were then tested for all of the defining relationships of equivalence and passed all of the tests. However, Hayes (1989) has argued that this result was not emergence as defined by Sidman and Tailby (1982) but, instead, was the result of direct training on all of the tested relations. For example, on identity trials, the monkey was trained A1-hold-A1-hold, A2-FR-A2-FR, B1-hold-B1-hold, and B2-FR-B2-FR. The trained relations on arbitrary matching trials were A1-hold-B1-hold and A2-FR-B2-FR. Thus, the animal learned to make a hold response after some stimuli (A1 and B1) and an FR response after others (A2 and B2). The problem is, however, that the common response also could have become a mediating stimulus for comparison choice. In other words, on trials in which a hold response was required, the monkey could have simply learned "after making a hold response, choose A1 or B1." On subsequent symmetry trials, the animal was required to make the following responses: B1-hold-A1-hold and B2-FR-A2-FR. Note that prior training directly included these test-trial requirements. Thus, it seems doubtful that these monkeys demonstrated any of the properties of equivalence.

Nakagawa (2001) conducted a study with rats using a T-maze. The rats were trained to run up the base of the $\mathrm{T}$ to observe a sample stimulus (e.g., A1 or A2). The comparisons (B1 and B2) were presented on the two arms of the $\mathrm{T}$, with a response bar located in front of each one. The sample remained on while the comparisons were presented. Rats were trained on A-B matching, overtrained on A-B matching, or trained on a pseudomatching task (not described in the study). The sample and comparison roles were then switched (and choices consistent with symmetry were reinforced). No evidence for symmetry was found on the first $\mathrm{B}-\mathrm{A}$ training session, but the rats given overtraining on $\mathrm{A}-\mathrm{B}$ matching learned the $\mathrm{B}-\mathrm{A}$ task faster than did the group trained just to criterion. Both of these groups learned the task faster than did the rats given pseudotraining. Despite these between-group differences in the rate of learning the test task, it is unclear that this result indicated symmetry. Typically, when samples and comparisons are reversed for a symmetry test, the B stimuli become samples and the A stimuli become the comparisons (e.g., the sample is B1 and the comparisons are A1 and A2). In this study, however, when a B stimulus (e.g., B1) was a sample, the comparisons were the class-consistent A stimulus and the other B stimulus (e.g., A1 and B2). Rats could have performed this task by means other than on the basis of symmetry. For instance, in training, it is possible that the rats learned the $\mathrm{A}-\mathrm{B}$ relation by rejecting the incorrect comparison rather than selecting the correct comparison (cf. Johnson \& Sidman, 1993). To illustrate, with A1 as the sample, the subject should reject B2 (and thus press the bar corresponding to the only other remaining stimulus, B1), and likewise, with A2 as the sample, the subject should reject B1 (and press the bar for B2). Now, recall that, during symmetry tests, the same three stimuli were presented simultaneously (although in a configuration different from that in training). In other words, with B1 presented as a sample, B2 and A1 were the comparisons. Assuming continuation of the reject $S$ - form of stimulus control, the rats would press the bar in front of $\mathrm{A} 1$, because responding away from B2 in the presence of B1 and A1 together had been established by training.

Bunsey and Eichenbaum (1996) trained a hippocampusdamaged group of rats and a sham-operated control group on a matching-to-sample task involving cups of scented sand. Reinforcers for correct matching of scents were buried in the correct comparison cups. The rats were trained on both $\mathrm{A}-\mathrm{B}$ and $\mathrm{B}-\mathrm{C}$ matching and were then tested for transitivity. They were next trained on $\mathrm{B}-\mathrm{A}$ matching to 
$78 \%$ or better accuracy prior to being tested for C-B symmetry. Rats were allowed to switch back and forth between comparisons until they retrieved the reinforcer, and the dependent variable was a preference index based on the amount of time spent digging in the correct (symmetrical) and incorrect comparisons. On the $\mathrm{C}-\mathrm{B}$ test, there were significant differences between the hippocampally damaged and control groups: The control group spent more time digging in the symmetrical comparison choice than did the hippocampus-damaged group. Whether or not the rats were demonstrating symmetry here is difficult to ascertain, however, because all test trials were reinforced, and no control for possible rapid learning of C-B matching due to reinforcement was included (such as a group reinforced for choices inconsistent with symmetry).

Studies with less than perfect symmetry. The next group of studies found varying degrees of evidence for symmetry. Some studies reported group designs in which statistical differences were found between groups, indicating symmetry. Others of these studies reported choice accuracies that statistically differed from chance but were well below $90 \%$. Also included are studies in which some subjects showed evidence for symmetry, whereas others did not, or a given subject demonstrated symmetry in some instances and not in others.

Tomonaga, Matsuzawa, Fujita, and Yamamoto (1991) tested for symmetry in 3 chimpanzees. Initial matchingto-sample training included both arbitrary and identity relations with which the subjects were trained in intermixed sessions. Samples and comparisons were presented on a computer touchscreen. A sample stimulus could appear anywhere on the top half of the screen, and the comparison stimuli could appear anywhere on the bottom half. Probe trials inserted into baseline sessions (consisting of arbitrary- and identity-matching trials) were used to test for symmetry. No reinforcement was given on the probe trials, and the probability of reinforcement on baseline trials was not reduced. One of the chimps matched at approximately $75 \%$ correct on probe trials (averaged over three sessions for a total of 24 symmetry trials; accuracy on the first 8 trials was $100 \%$ ), but the other 2 matched at chance. Testing in extinction may have been a factor on test trials. In a follow-up experiment with the 1 subject demonstrating symmetry, evidence was again obtained after unique stimuli (e.g., flashing screen or stars) were added to the task following both sample and comparison presentation for each defined class (e.g., stars were presented after responses to both $\mathrm{A} 1$ and $\mathrm{B} 1$, regardless of whether a correct choice was made).

Yamamoto and Asano (1995) tested for symmetry in 1 chimpanzee trained initially on identity (A-A, B-B) relations and then on arbitrary relations $(\mathrm{A}-\mathrm{B})$ using multiple stimulus sets. Then the reinforcement frequency on arbitrary (A-B) baseline trials was reduced, and unreinforced symmetry probes were inserted into sessions. The chimp was first given probes with one stimulus set only (e.g., B1-A1). If no evidence for symmetry was found, B1-A1 matching was directly trained with that stimulus set only. Then B2-A2 symmetry was tested. After training on several B-A relations, the chimp matched at $80 \%$ correct on a novel B-A (symmetry) relation (chance was 33\% in this study). However, in a subsequent symmetry test with new stimuli, accuracy was once again at chance.

Two studies (Urcuioli \& DeMarse, 1997; Zentall, Sherburne, \& Steirn, 1992) examined symmetry using matching tasks with class-specific outcomes that followed comparison selections in training. For example, Zentall et al. (1992) trained pigeons on identity and arbitrary matching in which correct choices of one comparison were followed by food (access to grain in a lit food hopper) and correct choices of the other comparison were followed by no food (no access to grain, but the food hopper was lit). No observing response to the samples was required in training; rather, each sample remained on for $6 \mathrm{sec}$ and was then followed by the display of comparison stimuli, regardless of the bird's behavior. In the testing session, food and no-food presentations were the samples (i.e., a lighted food hopper with or without food was presented) and were followed by choices between the same comparisons as those in training, using consistentand inconsistent-transfer groups. On the first test session, there was a significant difference between the groups: The consistent group matched above chance, and the inconsistent group matched below chance. In other words, the birds more often chose the comparison that had been followed by food in training when food was presented as a sample, and they more often chose the comparison that had not been followed by food in training when the nofood presentation was the sample. This result suggests a symmetrical relation between the comparison stimuli and the unique outcomes that followed them.

However, these data can also be explained by another process - mediated generalization - similar to that which could have been responsible for the findings of McIntire et al. (1987). Recall that no responses to the samples were required during training. In fact, however, the pigeons pecked more to one sample (the one related to the comparison whose selection produced food) than to the other (the one related to the comparison whose selection produced no food). It is plausible that, in training, comparison choices were mediated by pecking or not pecking rather than by the samples. In other words, the pigeons' behaviors with respect to the samples may have overshadowed the visual samples as controlling stimuli (cf. Urcuioli \& Honig, 1980). Furthermore, during testing, pigeons pecked at food samples but not at no-food samples. Thus, in both the training and the testing sessions, comparison choices could have been mediated by the presence or absence of pecking rather than by symmetrical relations or backward associations between the comparison and outcome stimuli.

However, Urcuioli and DeMarse (1997) conducted a similar manipulation that avoided this problem. Training ensured that pigeons pecked at similar rates to both samples by training on a one-to-many (i.e., sample-as-node) matching task. There were two sample stimuli, and each sample could be followed by two different sets of comparisons. For one set, correct choices resulted in the food out- 
come, and, for the other, correct choices resulted in the nofood outcome. For example, on some trials, Sample A was followed by Comparisons 1 and 2, and correct choices of Comparison 1 resulted in food. On other trials, Sample A was followed by Comparisons 3 and 4, and correct choices of Comparison 3 resulted in no food. Likewise, on some trials, Sample B was followed by Comparisons 1 and 2, and correct choices of Comparison 2 were followed by food. On other trials, Sample B was followed by Comparisons 3 and 4, and correct choices of Comparison 4 were followed by no food. In testing with previous outcomes as samples, these pigeons matched more accurately than did other pigeons that had been trained with common comparisonreinforcer relations, suggesting symmetrical relations between the visual comparison stimuli and the food and no-food outcomes. Because pecking or not pecking was not differentially associated with comparison choice, this result cannot be explained by mediated generalization.

García and Benjumea (2006) tested for symmetry in pigeons in a task in which the pigeons' own behavior was the sample. In Experiment 1, two response keys were lit white, and the pigeons were required to peck either the left or the right key. Comparisons were hues, and reinforcement was given for choosing one hue (e.g., red) after pecking left and the other hue (e.g., green) after pecking right. The symmetry test consisted of probe trials (always unreinforced) in which one of the former comparison stimuli was presented on both keys. To assess symmetry, García and Benjumea recorded where the pigeons initially pecked (the left or right key) and how many pecks were made to each location (a trial ended after 10 pecks were made, not necessarily on the same key). For instance, on some probes, red was presented on both the left and right keys. After a total of 10 pecks, the trial ended. Symmetry would be suggested if a greater proportion of pecks were made to the left key when red was presented and a greater proportion of pecks were made to the right key when green was presented. On probe trials, 9 of 10 pigeons' first responses on each trial were to the location suggesting symmetry (e.g., left when the keys were red and right when the keys were green). Moreover, when all required responses were considered, more than $60 \%$ of the pecks were made to the locations consistent with symmetry. Similar results were obtained in follow-up experiments with additional pigeons. Although these pigeons responded at levels that were statistically better than chance, the percentage of responses consistent with symmetry was still well below that typical of human subjects in many studies (although humans are not typically given the option of making multiple responses to multiple comparison stimuli).

Mixed evidence for symmetry in 3 capuchin monkeys was also recently reported by Santos, Barros, and Galvão (2003). Training began with simple discrimination and repeated discrimination reversals with two and then three stimuli that could appear in any of nine locations. Next, the monkeys were trained on identity relations with those stimuli. Tests for generalized identity matching followed (Barros et al., 2002), and the monkeys were not trained on arbitrary matching until they passed these tests.
Arbitrary-matching performances were trained using a stimulus-control shaping technique in order to minimize errors during training (i.e., to avoid the development of unwanted stimulus-control topographies; cf. McIlvane, Serna, Dube, \& Stromer, 2000).

Prior to a symmetry test, the monkeys were given a series of tests to assess the controlling relations between the samples and comparisons. Specifically, the monkeys were tested to determine whether select (i.e., the subject would select a particular comparison after a given sample) or reject (i.e., the subject would reject a particular comparison - and press the remaining comparison - after a given sample) controlling relations were present (cf. Johnson \& Sidman, 1993). If neither select nor reject relations were present, the subjects were directly trained. Santos et al. (2003) believed that it was essential that a monkey's choices be based on select control, and the procedure they used to verify this behavior requirement necessitated the inclusion of reject control trials as well. Three monkeys progressed to a symmetry test (a session in which unreinforced symmetry probes were inserted into a baseline session). The results were equivocal. One monkey performed below chance level on initial probes, was retrained to ensure the presence of both select and reject relations, and then matched at $90 \%$ correct on a symmetry retest. A second monkey performed at chance on two symmetry tests (with baseline retraining and class-specific reinforcement between the two). The third monkey did perfectly on its first symmetry test (B-A matching that followed $\mathrm{A}-\mathrm{B}$ training). It was then trained on a new arbitrary relation $(\mathrm{B}-\mathrm{C})$ and given three additional symmetry tests with those stimuli, on which it matched at or below chance. Interestingly, no identity training was given with the $\mathrm{C}$ stimuli (although this monkey did pass prior tests for generalized identity matching).

\section{Studies Reporting Clear Evidence}

There are two reported studies showing evidence for symmetry in 2 sea lions (Kastak, Schusterman, \& Kastak, 2001; Schusterman \& Kastak, 1993) and one study showing evidence for symmetry in pigeons (Frank \& Wasserman, 2005).

Schusterman and Kastak (1993) were the first to show strong evidence for stimulus equivalence in a nonhuman animal. Their training regimen was designed to give the subject experience with stimuli switching roles (i.e., between sample and comparison) prior to the critical tests. They used what is called the simple-to-complex training protocol by Fields et al. (1993). First, training establishes matching-to-sample relations, and tests for symmetry are given. After symmetry is demonstrated, transitivity is tested and confirmed, and finally, equivalence $(\mathrm{C}-\mathrm{A})$ is tested. The sea lion was trained on matching-to-sample with 30 stimulus sets (A1-A30, B1-B30, C1-C30) to establish three-member classes (A1, B1, C1; A2, B2, C2; etc.). Initial training consisted of $\mathrm{A}-\mathrm{B}$ matching with all 30 sets to high accuracy. Then the sea lion was given symmetry tests with stimuli from 12 of the stimulus sets, 6 sets at a time. If symmetry was not initially demonstrated, the 
stimulus relations used in the tests were established by direct training to a high accuracy criterion. Then the second 6 sets were included in testing. The subject was then trained on the relations between B and C stimuli with all 30 sets and was again tested for symmetry with 12 of the stimulus sets, as well as for transitivity $(\mathrm{A}-\mathrm{C})$ and equivalence $(\mathrm{C}-\mathrm{A})$.

Symmetry tests consisted of reinforced probe trials inserted into a session consisting of baseline trials. Evidence for symmetry was defined as (1) no more than one error on probe trials and (2) no error on the first probe trial. On a B-A symmetry test with the first 6 sets, the sea lion passed half of the tests (chance performance). On the $\mathrm{B}-\mathrm{A}$ test with the second 6 stimulus sets, the sea lion passed five tests. When C-B symmetry was subsequently tested, the sea lion passed tests with 10 of the 12 stimulus sets (in addition, it passed most tests for transitivity and equivalence). Schusterman and Kastak (1993) attributed the sea lion's success to a history of multiple exemplar training (i.e., reinforced history of responding consistent with symmetry with some stimulus sets) and to the use of multiple $\mathrm{S}-$ stimuli during training. This ensured that the negative comparison did not become part of the equivalence class (i.e., reject control was not possible).

In a later study (Kastak et al., 2001), the aforementioned sea lion and an additional sea lion were tested for equivalence in a different format. The sea lions were first trained on a series of simple simultaneous discriminations and their repeated reversals in order to create two functional classes of stimuli (stimuli classified together because they all share a common function; cf. Vaughan, 1988). After reliable functional classes were established, the sea lions were transferred to conditional (matchingto-sample) discriminations using those stimuli to see whether they would match stimuli belonging to the same functional class. Finally, the sea lions were trained to relate novel stimuli to some of the existing class members and were subsequently tested for equivalence between the novel stimuli and the remaining class members. Both sea lions showed functional class formation, but only when correct responding to the stimuli was reinforced with class-specific outcomes. When nondifferential outcomes were substituted, the classes degraded. In addition, when transferred to a matching-to-sample task, the sea lions were able to match stimuli belonging to the same functional classes without explicit training to do so. Finally, after being trained to match novel stimuli to a subset of the stimuli from the functional classes, the sea lions were tested for equivalence between the novel stimuli and the remaining functional class members. Both sea lions passed the tests, indicating the existence not only of symmetrical but also of transitive relations.

Finally, Frank and Wasserman (2005) reported the strongest evidence to date for symmetry in pigeons. Pigeons were trained on successive matching-to-sample (e.g., Richards, 1988) in order to control for location variables. Training included $\mathrm{A}-\mathrm{B}$ as well as $\mathrm{A}-\mathrm{A}$ and $\mathrm{B}-\mathrm{B}$ identity relations in an intermixed session to control for temporal variables (i.e., a given stimulus could appear at either the beginning of a trial as a sample or in the middle of the trial as a comparison). Stimuli were clip-art pictures presented on a computer screen with a touch-sensitive panel in a single location. Samples and comparisons were each presented for $10 \mathrm{sec}$, with $3.5 \mathrm{sec}$ between sample and comparison presentations. Peck rates during stimulus presentation were recorded. Pigeons remained in training until reaching a discrimination ratio of .80 . On half of the training trials, a sample was followed by a correct comparison followed by access to grain. On the remaining trials, a sample was followed by an incorrect comparison and no access to grain. Thus, on half of the training trials, no reinforcement was given. Symmetry testing consisted of unreinforced $\mathrm{B}-\mathrm{A}$ probe trials inserted into a session consisting of baseline (A-B, A-A, and B-B) trials. After one test session, the pigeons experienced a return to baseline without probe trials until discrimination ratios were at least .80 and then a second test session with probe trials. Two pigeons were tested on this procedure, and both pigeons pecked more to comparisons consistent with symmetry than to comparisons inconsistent with symmetry.

In a follow-up experiment, 2 different pigeons were given similar training, but without the intermixing of identity-matching trials. Instead, these 2 pigeons were trained only on arbitrary matching and were then given symmetry tests. In contrast to the first 2 pigeons, these pigeons pecked at similar rates to comparisons that were consistent and inconsistent with a symmetrical relation on probe trials. In a final experiment, 2 additional pigeons were trained on arbitrary relations only prior to a symmetry test. Then, intermixed identity trials were added to the baseline of arbitrary-matching trials prior to a second symmetry test. On the symmetry test just after arbitraryrelations-only training, the pigeons pecked at similar rates to the comparisons consistent and inconsistent with a symmetrical relation, replicating the findings of Experiment 2. After subsequent intermixed identity training, 1 pigeon began to peck more frequently at the comparison consistent with symmetry than at the comparison inconsistent with symmetry, thus showing the emergence of symmetry only after identity matching was added to the baseline.

The successive-matching procedure, however, is not a panacea. In a recent Psychonomic Society presentation, Urcuioli, Michalek, and Lionello-DeNolf (2006) reported training pigeons on a procedure like Frank and Wasserman's (2005; see also Urcuioli, 2008). The main difference between the studies was the apparatus: Urcuioli et al. used the standard three-key pigeon chamber with hue and line stimuli. Four of the 7 pigeons tested had discrimination ratios of .75 or above over the first two symmetry test sessions, indicating the emergence of symmetry in these pigeons. The reason that the remaining 3 pigeons did not show symmetry is unclear, but may be related to procedural details that differed between the studies (such as intertrial interval length or stimuli). This warrants further study.

\section{SUMMARY AND CONCLUSIONS}

Twenty-four studies investigating symmetry in animals were reviewed. In these studies, there were 229 experi- 
Iable 2

\begin{tabular}{lccc}
\multicolumn{4}{c}{$\begin{array}{c}\text { Species, } \\
\text { Number of Subjects, and Number of Subjects } \\
\text { Showing Emergent Symmetry }\end{array}$} \\
\hline Species & $\begin{array}{c}\text { Total Number } \\
\text { of Subjects }\end{array}$ & $\begin{array}{c}\text { Subjects Showing } \\
\text { Symmetry }\end{array}$ & $\begin{array}{c}\text { Percentage Showing } \\
\text { Symmetry }\end{array}$ \\
\hline Pigeon & 182 & 76 & 42 \\
Monkey & 15 & 5 & 33 \\
Baboon & 2 & 0 & 0 \\
Chimpanzee & 6 & 2 & 33 \\
Rat & 22 & 10 & 45 \\
Sea lion & 2 & 2 & 100 \\
Total & 229 & 95 & 41 \\
\hline
\end{tabular}

Note-For studies in which only group data were reported, it was assumed that no subjects showed symmetry if the overall result was negative and that all subjects did show symmetry if the overall result was positive.

mental subjects, including pigeons (182), rats (22), primates (23), and sea lions (2) (see Table 2). Approximately $95(41 \%)$ of these animals showed some evidence of symmetry. Use of one particular species did not increase the likelihood of demonstrating symmetry: $42 \%$ of pigeons, $30 \%$ of primates, and $45 \%$ of rats did. Note, however, that the number for rats is most likely inflated, because the rat studies involved group designs, and individual subject data were not reported.

Although 11 of the reviewed studies failed to find evidence for symmetry ( $45 \%$ ), the remaining $55 \%$ found either mixed evidence (10 studies) or strong evidence (3 studies). There were clear procedural differences between the two latter groups of studies and the former that would have influenced the likelihood of finding the effect. Sidman et al. (1982) speculated that certain experiences were absent from their subjects' baseline and preexperimental histories that were critical for the formation of symmetrical relations (which is probably not the case for humans). Specifically, they suggested a history of multiple exemplar training, stimulus location control procedures, and a history of generalized identity matching. In addition, they believed that individual species differences would render other, as yet unidentified variables important. Sidman et al.'s (1982) analysis proved to be prescient.

One variable identified by Sidman et al. (1982) that has been shown to be important is multiple exemplar training. Recall that Schusterman and Kastak (1993) tested a sea lion on symmetry with only a subset of the original training stimuli. Then the subject was directly trained on symmetry with that subset, prior to additional tests for emergent symmetry with the remaining stimuli. Symmetry was evident after the sea lion had been trained on several symmetrical associations. There is another example of success after multiple exemplar training in the literature, although the concept involved was not symmetry. Katz and Wright (2006) used a similar procedure to test for emergent same-different performance in pigeons and found evidence of such emergence after a large number of training examples. Why the multiple exemplar training procedure was effective for symmetry is not clear. One reason may be that training the multiple examples of symmetry meant that the samples and comparisons were now appearing in new locations, and, thus, control by stimulus location may have been reduced. In other words, maybe learning that some samples and comparisons can appear in multiple locations was sufficient for the generalization that all stimuli can appear in all the locations.

Perhaps exemplar training was effective because it reduces control not only by where a stimulus appears, but also by when it appears. In other words, the fact that samples always appeared first in a trial and comparisons second may have become a salient stimulus characteristic that gained control over behavior. One cause of this outcome may be the unidirectional nature of the trials. Responding to sample stimuli was never reinforced but was always followed by a choice between comparisons, and correct choices were followed by reinforcement. Of course, this is true for human subjects as well, but, for animals, the reinforcer has biological significance (e.g., food), whereas, for humans, it does not (e.g., points, money, course credit). Moreover, humans have extensive preexperimental experience of bidirectional relationships between objects or events that animals lack. Multiple exemplar or symmetry training may thus emphasize that certain stimuli go together and reduce the saliency of directionality. Why, then, was such training not successful in facilitating emergent symmetry in the two other studies reviewed here that used it? One reason may be that although the chimpanzees tested by Dugdale and Lowe (2000) had a history of bidirectional responding to object and lexigram stimuli, this experience was remote from the experimental situation and involved stimuli vastly different from those used in the critical symmetry test. Moreover, other procedural factors, such as the lack of reinforcement on test trials, may have contributed. The remaining study, Lionello-DeNolf and Urcuioli (2002), provided a history of symmetry with only two stimulus sets, which was most likely an insufficient number. The sea lion did not show symmetry until after training on at least six stimulus sets. Moreover, the pigeons tested by Katz and Wright (2006) for samedifferent concept learning did not show emergence until after training with approximately 256 stimulus sets.

Prior to Sidman et al. (1982), the traditional assessment method had been to train arbitrary A-B matching, and then simply to test for B-A matching. In addition, it became typical to present the sample stimulus in an invariant central location and the comparison stimuli (usually two but sometimes three) on side locations or in a row beneath the sample. Unfortunately, this procedure - although rou- 
tinely successful with humans - seems to be the one least likely to yield symmetry in animals. Seven of the reviewed studies used this training procedure, and only two (29\%) showed at least mixed evidence for symmetry. Moreover, those two (Bunsey \& Eichenbaum, 1996; Nakagawa, 2001) both have alternative explanations of the data.

Table 1 indicates that when researchers deviated from the typical training procedure, animals were more likely to show symmetry. One deviation was to train identitymatching relations, often as a procedure for reducing control by stimulus location. Six studies used identity matching as the sole method of location control, and four (66\%) found at least mixed evidence for symmetry. Another deviation was to use a test procedure that explicitly controlled location (e.g., training with multiple locations, using only one location, etc.). Six studies did so and did not also include additional identity training. Of those, three (50\%) showed at least mixed evidence for symmetry. Interestingly, five studies included both identity training and additional location procedures, and four of them (80\%) showed some evidence for symmetry. Thus, as Sidman et al. (1982) predicted, controlling for the effects of stimulus location seems to aid the emergence of symmetry, particularly if it is combined with additional identity training.

Evidence of symmetry was also more likely when alternatives to three-key matching-to-sample procedures were used. Although only a few of the studies failing to find evidence of symmetry used alternative procedures (e.g., Barros et al., 1996; Lipkens et al., 1988; Richards, 1988), a majority of the mixed-evidence studies did. Often, these studies took advantage of some of the species-specific variables referred to by Sidman et al. (1982). For example, Bunsey and Eichenbaum (1996) presented odor cues to rats, and Zentall et al. (1992) and Urcuioli and DeMarse (1997) used biologically important stimuli (i.e., the presence and absence of food) as discriminative stimuli.

\section{Why Is Symmetry More Likely With Alternative Procedures?}

It seems evident that symmetry performances can be encouraged (or discouraged) by the type of training procedure used. The most effective alternative procedure is one that provides training on identity relations and also explicitly controls for stimulus location effects. Two reasons that identity training may be needed in addition to explicit location controls is that identity training ensures that the animals can make successive and simultaneous discriminations between the stimuli (prerequisites for symmetry) and may control temporal variables (i.e., animals learn that a given stimulus can appear either first as a sample or second as a comparison). This review suggests that the importance of identity training may go beyond these variables. When studies employing identity training are considered, some evidence for symmetry has been found whenever trials involving identity matching were intermixed with arbitrary matching training: Out of four studies, three found mixed evidence, and one found strong evidence (but see Urcuioli, 2008). However, when identity training took place separately from arbitrary-matching training (i.e., before or after A-B relations were learned), evidence for symmetry was less compelling: Out of seven studies, three found no evidence, two found mixed evidence, and two found strong evidence. Possibly, studies that included intermixed identity training with arbitrary training were successful because they increased the likelihood for consistent select controlling relations between the sample stimulus and the reinforced comparison. Interestingly, among the seven studies that included identity relations trained separately from arbitrary ones, three included training that may have encouraged consistent select (or reject) controlling relations (the rightmost column of Table 1 indicates in which studies training procedures may have encouraged select or reject control). In what follows, I will consider this and related possibilities in more detail.

Select and reject control. When a conditional discrimination is performed, it is logically possible to make a comparison choice by selecting a particular comparison after a given sample on all trials, by rejecting a particular comparison (and responding to the opposite comparison) on all trials (Carrigan \& Sidman, 1992), by doing both, or by doing a combination of these possibilities across trials in a session. If one assumes select control at the end of A-B arbitrary-matching training, emergent symmetrical relations could logically result: The animal learns that A and B stimuli go together, so that in the testing session, it chooses A1 after B1 and A2 after B2. Consider the possibility, however, that, in baseline training, the animal performs the task by rejecting B2 after A1 (touching B1) and rejecting B1 after A2 (touching B2). Johnson and Sidman (1993) argued that even if A-B matching is under such reject control, symmetry is still predicted, because the reject relation between the A and $\mathrm{B}$ stimuli still holds (e.g., if "see A1, reject B2" is learned, then in the testing session, the subject should "see B2, reject A1" and therefore touch A2). Evidence from their human subjects has further confirmed symmetry when arbitrary matching explicitly establishes reject control.

In the absence of special training procedures to bias the subject toward a particular controlling relation, will exclusive select or exclusive reject control develop? Logically, the animal could display reject control on some baseline trials and select control on others. Early in training, when accuracy on the matching problems is at chance, the animals' choices could be governed by a mixture of stimulus properties, termed stimulus-control topographies by Dube and McIlvane (1996). As training continues, however, differential reinforcement would tend to favor development of control by stimulus aspects consistent with the experimenter-defined relations. In the case of two-choice matching-to-sample, both select and reject control could be reinforced throughout training, because both are compatible with the training contingencies. Thus, by the end of training, choice on some trials could be due to select relations and choice on other trials to reject relations. Notably, the baseline accuracy score would not reveal these controlling relations. Moreover, in the human literature, there is strong evidence that conditional discrimination performance may be governed concurrently by select and reject control (Dixon \& Dixon, 1978; Stromer \& Osborne, 
1982). In addition, recent data from the simultaneous discriminations of Cebus apella suggest that both select and reject control are possible in the same baseline (Goulart, Mendonça, Barros, Galvão, \& McIlvane, 2005).

To the extent that the animal's performances represent an uneven mixture of select and reject control within and across trials just prior to test, symmetry outcomes become uncertain. For example, suppose that the nature of an animal's baseline performance could be described thus: "If A1, then select B1; if anything else, then reject B1." In the testing session, it is difficult to specify a predicted basis for the animal's performance. If matching $\mathrm{A} 1$ to $\mathrm{B} 1$ is symmetrical, performance on trials with B1 as a sample would be based on "if B1, then select A1," resulting in high accuracy on those trials. But what about on trials that displayed B2 as the sample? Because the baseline selections of B2 were made by rejecting B1 in relation to all nonA1 samples, discrimination of the defining features of B2 was never established (i.e., "if B2, then select [what]?"). Expecting the emergence of "if the sample is anything other than B1, then select anything other than A1 (or reject A1)" does not follow. Of course, this is just one example of any number of select/reject control patterns that could develop during training (e.g., see the example involving specific stimulus configurations below). Potentially, such test situations may set up an impossible discrimination of the sort that may abolish discrimination baselines (Stoddard \& Sidman, 1971).

Potentially compounding this problem, nonhuman baseline performances are only rarely at or near perfection (which can be contrasted to that of typical humans in many studies). If baseline accuracy is only $85 \%-90 \%$, for example, the proportion of irrelevant, typically unidentified controlling relations involving position and/or local trial effects can be estimated at $20 \%-30 \%$ in a two-comparison task (Dube \& Mcllvane, 1996). These controlling relations may also be incompatible with symmetry (cf. McIlvane et al., 2000), perhaps interacting with select/reject controlling relations in unpredictable ways. For instance, consider a situation in which, on trials with one sample, the animal's choice is under select control (e.g., "if the sample is red, choose the vertical line"), but on trials with the other sample, the animal's choice is a combination of configural and select/reject control (e.g., "if a green sample is followed by a vertical line on the left and a horizontal line on the right, reject the vertical line," and "if a green sample is followed by a vertical line on the right and a horizontal line on the left, select the horizontal line"). Such behavioral variability could lead to unpredictable results at test.

Carrigan and Sidman (1992) suggested that identitymatching trials may be more likely than other trial types to occasion select control. We do not know empirically, however, whether identity trials do in fact render select control more likely. Some data suggest that when pigeons are trained on matching-to-sample in which an identity relation is involved, the development of select versus reject controlling relations depends on reinforcement contingencies (Zentall, Edwards, Moore, \& Hogan, 1981). Zentall et al. (1981) trained pigeons on either matching-to-sample or oddity-from-sample and subsequently replaced either the correct or incorrect comparisons with another (familiar) stimulus. Pigeons trained on the matching task were more accurate on trials in which the incorrect comparison was replaced than on those in which correct comparison was replaced, suggesting select control. Pigeons trained on the oddity task, however, were more accurate on trials in which the correct comparison was replaced than on those in which the incorrect comparison was replaced, suggesting reject control. The overall pattern of results suggests a conceptual relation between the samples and comparisons based on identity and, importantly, is consistent with Carrigan and Sidman's assertion that identity training tends to engender select control in matching-to-sample.

Regarding symmetry, important variables may well prove to be the nature and consistency of controlling relations across trials (i.e., all select relations, all reject relations, or select and reject relations involving all of the sample-comparison relations). Data cited above from both pigeons (Zentall et al., 1981) and monkeys (Goulart et al., 2005) indicate that animals' choices on matching tasks can be based on either select or reject controlling relations. If the identity-matching procedure does in fact foster development of consistent select control, for example, intermixing identity- and arbitrary-matching training trials within a session may make it more likely that consistent select control develops overall (i.e., not only on the $\mathrm{A}-\mathrm{A}$ and $\mathrm{B}-\mathrm{B}$ trials, but also on the $\mathrm{A}-\mathrm{B}$ matching trials). In such a situation, stimulus equivalence relations, including symmetry, may be more likely to be observed.

The training approach used by Schusterman and Kastak (1993) may have encouraged consistent select control. They used a two-choice matching procedure in which a different incorrect comparison was presented on every baseline trial. Thus, the number of possible reject relations greatly exceeded the number of possible select relations, and the procedure would thus be expected to render the latter more probable (cf. Cumming \& Berryman, 1965). In addition, the sea lion's history of generalized identity matching may have encouraged select control. Interestingly, the successive matching procedure, used in the successful demonstration of symmetry in pigeons (Frank \& Wasserman, 2005), may have engendered select as well as reject control as follows. On every trial, only one comparison was presented after each sample. On half of the trials, therefore, a sample was followed by an incorrect comparison, and the pigeons had to refrain from responding. In other words, by the end of training, the pigeons were forced to learn to respond to each matching samplecomparison pair (select control) and to refrain from responding to each nonmatching sample-comparison pair (reject control).

Notably, some studies showing mixed evidence employed neither intermixed identity training nor training that explicitly encouraged select control. They did, however, employ other alternative procedures that may have capitalized on unique characteristics for the population studied. We do not know whether such procedures led to partial success because they encouraged consistent select or reject controlling relations, because they encouraged stimulus-control topography coherence, or for 
some other reason (see, e.g., Urcuioli, 2008). They do, however, underscore the point that standard procedures as typically implemented on a three-key apparatus are insufficient by themselves to produce emergent symmetry in nonhumans.

\section{FUTURE DIRECTIONS}

This review has suggested that replicable, reliable symmetry may be achievable with nonhumans if training and test procedures that encourage compatible stimuluscontrol topographies and relations are designed. Such a procedure needs to demonstrate that the animal can make both successive and simultaneous discriminations between all of the stimuli involved and control for stimulus location variables. Moreover, baseline-training procedures should ensure consistent select and/or reject controlling relations. One possibility is to intermix identity-matching trials with arbitrary ones from the onset of baseline training. To minimize or eliminate control by location, one could use a successive matching procedure or a procedure in which samples and comparisons are presented in many locations throughout training. Animals trained in this manner may be more likely to show symmetry than those trained similarly but without identity training or without intermixed identity training. Additional procedures can also be employed to determine both the presence and absence of select and reject controlling relations between the stimuli, and even to bias the subject toward select or reject control. These ideas are testable and will bring us a step closer to understanding the nature and possibility of symmetrical relations in nonhumans.

\section{AU'THOR NOTE}

Manuscript preparation was supported by Grants HD39816 and HD04147 from the Eunice Kennedy Shriver National Institute of Child Health and Human Development. An earlier version of this article was submitted to the faculty of Purdue University in partial fulfillment of the requirements of the PhD degree. I thank Bill Dube, Harry MacKay, Peter Urcuioli, John Capaldi, Terry Davidson, and Jim Nairne — and especially Bill McIlvane-for their comments and insights. Correspondence concerning this article should be sent to K. M. Lionello-DeNolf, UMMS Shriver Center, 200 Trapelo Rd., Waltham, MA 02452 (e-mail: karen .lionello-denolf@umassmed.edu).

\section{REFERENCES}

Arcediano, F., Escobar, M., \& Miller, R. R. (2003). Temporal integration and temporal backward associations in human and nonhuman subjects. Learning \& Behavior, 31, 242-256.

Asch, S. E., \& Ebenholtz, S. M. (1962). The principle of associative symmetry. Proceedings of the American Philosophical Society, 106, 135-163.

BARnet, R. C., \& Miller, R. R. (1996). Second-order excitation mediated by a backward conditioned inhibitor. Journal of Experimental Psychology: Animal Behavior Processes, 22, 279-296.

Barros, R. S., Galvão, O. F., \& Fontes, J. C. S. (1996). Um teste de simetria após treino de relaçôes condicionais de posição com macaco Ateles paniscus paniscus. Acta Comportamentalia, 4, 181-204.

Barros, R. S., Galvão, O. F., \& McIlvane, W. J. (2002). Generalized identity matching-to-sample in Cebus apella. Psychological Record, 52, 441-460.

Bartling, C. A., \& Thompson, C. P. (1977). Encoding specificity:
Retrieval asymmetry in the recognition failure paradigm. Journal of Experimental Psychology: Human Learning \& Memory, 3, 690-700.

Bunch, M. E., \& Lund, W. R. (1932). An experiment on backward associations in animal learning. Journal of Comparative Psychology, 13, 143-156.

Bunsey, M., \& Eichenbaum, H. (1996). Conservation of hippocampal memory function in rats and humans. Nature, 379, 255-257.

CARr, D., Wilkinson, K. M., Blackman, D., \& McIlvane, W. J. (2000). Equivalence classes in individuals with minimal verbal repertoires. Journal of the Experimental Analysis of Behavior, 74, 101-114.

CARR, H. A., \& FreEman, A. S. (1919). Time relationships in the formation of associations. Psychological Review, 26, 465-473.

CARRIGan, P. F., \& Sidman, M. (1992). Conditional discrimination and equivalence relations: A theoretical analysis of control by negative stimuli. Journal of the Experimental Analysis of Behavior, 58, 183-204.

Coutu, E. W. (1966). Associative asymmetry in paired associates. Psychonomic Science, 5, 389-390.

Cumming, W. W., \& Berryman, R. (1965). The complex discriminated operant: Studies of matching-to-sample and related problems. In D. I. Mostofsky (Ed.), Stimulus generalization (pp. 284-330). Stanford: Stanford University Press.

D’Amato, M. R., Salmon, D. P., Loukas, E., \& Tomie, A. (1985). Symmetry and transitivity of conditional relations in monkeys (Cebus apella) and pigeons (Columba livia). Journal of the Experimental Analysis of Behavior, 44, 35-47.

Delamater, A. R., LoLordo, V. M., \& Sosa, W. (2003). Outcomespecific conditioned inhibition in Pavlovian backward conditioning. Learning \& Behavior, 31, 393-402.

Devany, J. M., HaYes, S. C., \& Nelson, R. O. (1986). Equivalence class formation in language-able and language-disabled children. Journal of the Experimental Analysis of Behavior, 46, 243-257.

Dixon, M. H., \& DixON, L. S. (1978). The nature of standard control in children's matching-to-sample. Journal of the Experimental Analysis of Behavior, 30, 205-212.

DorCAs, M. D. (1932). The establishing of backward associations in forward learning of the maze by albino rats. Journal of Comparative Psychology, 13, 11-18.

Dube, W. V., \& Mcllvane, W. J. (1996). Some implications of a stimulus control topography analysis for emergent stimulus classes. In T. R. Zentall \& P. M. Smeets (Eds.), Stimulus class formation in humans and animals (pp. 197-218). Amsterdam: Elsevier.

Dugdale, N., \& Lowe, C. F. (2000). Testing for symmetry in the conditional discriminations of language-trained chimpanzees. Journal of the Experimental Analysis of Behavior, 73, 5-22.

Ebbinghaus, H. (1913). Memory (H. A. Ruger \& C. E. Bussenius, Trans.). New York: Columbia University, Teachers College. (Original work published 1885)

Eikeseth, S., \& Smith, T. (1992). The development of functional and equivalence classes in high-functioning autistic children: The role of naming. Journal of the Experimental Analysis of Behavior, 58, 123133.

Fields, L., Adams, B. J., Brown, J. L., \& Verhave, T. (1993). The generalization of emergent relations in equivalence classes: Stimulus substitutability. Psychological Record, 43, 235-254.

Frank, A. J., \& Wasserman, E. A. (2005). Associate symmetry in the pigeon after successive matching-to-sample training. Journal of the Experimental Analysis of Behavior, 84, 147-165.

García, A., \& Benjumea, S. (2006). The emergence of symmetry in a conditional discrimination task using different responses as proprioceptive samples in pigeons. Journal of the Experimental Analysis of Behavior, 86, 65-80.

Goulart, P. R. K., Mendonça, M. B., Barros, R. S., Galvão, O. F., \& McIlvane, W. J. (2005). A note on select- and reject-controlling relations in the simple discrimination of capuchin monkeys (Cebus apella). Behavioural Processes, 69, 295-302.

Gray, L. (1966). Backward association in pigeons. Psychonomic Science, 4, 333-334.

HaYes, S. C. (1989). Nonhumans have not yet shown stimulus equivalence. Journal of the Experimental Analysis of Behavior, 51, 385-392.

Hayes, S. C., Barnes-Holmes, D., \& Roche, B. (2001). Relational frame theory: A précis. In S. C. Hayes, D. Barnes-Holmes, \& B. Roche 
(Eds.), Relational frame theory: A post-Skinnerian account of human language and cognition (pp. 141-154). New York: Kluwer/Plenum.

Hayes, S. C., Gifford, E. V., \& Wilson, K. G. (1996). Stimulus classes and stimulus relations: Arbitrary applicable relational responding as an operant. In T. R. Zentall \& P. M. Smeets (Eds.), Stimulus class formation in humans and animals (pp. 279-299). Amsterdam: Elsevier.

Hearst, E. (1989). Backward associations: Differential learning about stimuli that follow the presence versus the absence of food in pigeons. Animal Learning \& Behavior, 17, 280-290.

Herman, L. M., \& Gordon, J. A. (1974). Auditory delayed matching in the bottlenose dolphin. Journal of the Experimental Analysis of Behavior, 21, 19-26.

Herman, L. M., Hovancik, J. R., Gory, J. D., \& Bradshaw, G. L. (1989). Generalization of visual matching by a bottlenose dolphin (Tursiops truncates): Evidence for invariance of cognitive performance with visual and auditory materials. Journal of Experimental Psychology: Animal Behavior Processes, 15, 124-136.

Hogan, D. E., \& Zentall, T. R. (1977). Backward associations in the pigeon. American Journal of Psychology, 90, 3-15.

Holmes, P. W. (1979). Transfer of matching performance in pigeons. Journal of the Experimental Analysis of Behavior, 31, 103-114.

HoRNE, P. J., \& LowE, C. F. (1996). On the origins of naming and other symbolic behavior. Journal of the Experimental Analysis of Behavior, $\mathbf{6 5}, 185-242$.

IVERSEN, I. (1997). Matching-to-sample performance in rats: A case of mistaken identity? Journal of the Experimental Analysis of Behavior, 68, 27-47.

Iversen, I., Sidman, M., \& Carrigan, P. (1986). Stimulus definition in conditional discriminations. Journal of the Experimental Analysis of Behavior, 45, 297-304.

Johnson, C., \& Sidman, M. (1993). Conditional discrimination and equivalence relations: Control by negative stimuli. Journal of the Experimental Analysis of Behavior, 59, 333-347.

Kahana, M. J. (2002). Associative symmetry and memory theory. Memory \& Cognition, 30, 823-840.

Kastak, C. R., Schusterman, R. J., \& Kastak, D. (2001). Equivalence classification by California sea lions using class-specific reinforcers. Journal of the Experimental Analysis of Behavior, 76, 131-158.

Katz, J. S., \& WRIGHT, A. A. (2006). Same/different abstract-concept learning by pigeons. Journal of Experimental Psychology: Animal Behavior Processes, 32, 80-86.

Keith-Lucas, T., \& GutTman, N. (1975). Robust single-trial delayed backward conditioning. Journal of Comparative \& Physiological Psychology, 88, 468-476.

Kendall, S. B. (1983). Tests for mediated transfer in pigeons. Psychological Record, 33, 245-256.

Kuno, H., Kitadate, T., \& Iwamoto, T. (1994). Formation of transitivity in conditional matching to sample by pigeons. Journal of the Experimental Analysis of Behavior, 62, 399-408.

Levy, C. M., \& NeviLl, D. D. (1974). B-A learning as a function of degrees of A-B learning. Journal of Experimental Psychology, 102, 327-329.

Lionello, K. M., \& Urcuioli, P. J. (1998). Control by sample location in pigeons' matching to sample. Journal of the Experimental Analysis of Behavior, 70, 235-251.

Lionello-DeNolf, K. M., \& Urcuioli, P. J. (2000). Transfer of pigeons' matching-to-sample to novel sample locations. Journal of the Experimental Analysis of Behavior, 73, 141-161.

Lionello-DeNolf, K. M., \& Urcuioli, P. J. (2002). Stimulus control topographies and test of symmetry in pigeons. Journal of the Experimental Analysis of Behavior, 78, 467-495.

Lipkens, R., Kop, P. F. M., \& Matthiss, W. (1988). A test of symmetry and transitivity in the conditional discrimination performances of pigeons. Journal of the Experimental Analysis of Behavior, 49, 395-409.

LOCKHART, R. S. (1969). Retrieval asymmetry in the recall of adjectives and nouns. Journal of Experimental Psychology, 79, 12-17.

Mandler, G., Rabinowitz, J. C., \& Simon, R. A. (1981). Coordinate organization: The holistic representation of word pairs. American Journal of Psychology, 92, 209-222.

McIlvane, W. J., Serna, R. W., Dube, W. V., \& Stromer, R. L. (2000). Stimulus control topography coherence and stimulus equivalence:
Reconciling test outcomes with theory. In J. Leslie \& D. E. Blackman (Eds.), Experimental and applied analysis of human behavior (pp. 85110). Reno: Context Press.

MCIntire, K. D., Cleary, J., \& Thompson, T. (1987). Conditional relations by monkeys: Reflexivity, symmetry, and transitivity. Journal of the Experimental Analysis of Behavior, 47, 279-285.

Moscovitch, A., \& LoLordo, V. M. (1968). Role of safety in the Pavlovian backward fear conditioning procedure. Journal of Comparative \& Physiological Psychology, 68, 673-678.

Murdock, B. B., JR. (1962). The serial position effect of free recall. Journal of Experimental Psychology, 64, 482-488.

Murdock, B. B., JR. (1966). Forward and backward associations in paired associates. Journal of Experimental Psychology, 71, 732-737.

NAKAGaWA, E. (2001). Acquired equivalence of cues in learning a matching-to-sample task by rats. Psychological Record, 51, 453-467.

Oden, D. L., Thompson, R. K., \& Premack, D. (1988). Spontaneous transfer of matching by infant chimpanzees (Pan troglodytes). Journal of Experimental Psychology: Animal Behavior Processes, 14, 140-145.

Pavlov, I. P. (1928). Lectures on conditioned reflexes. New York: International Publishers.

PeÑa, T., Pitts, R. C., \& Galizio, M. (2006). Identity matching-tosample with olfactory stimuli in rats. Journal of the Experimental Analysis of Behavior, 85, 203-221.

Razran, G. (1956). Backward conditioning. Psychological Bulletin, 53, 55-69.

RICHARDS, R. W. (1988). The question of bidirectional associations in pigeons' learning of conditional discrimination tasks. Bulletin of the Psychonomic Society, 26, 577-579.

Rodewald, H. K. (1974). Symbolic matching-to-sample by pigeons. Psychological Reports, 34, 987-990.

Santos, J. R., Barros, R. S., \& Galvão, O. (2003, May). Symmetry in Cebus apella. Paper presented at the 29th Annual Meeting of the Association for Behavior Analysis, San Francisco.

Saunders, K. J., \& Spradlin, J. E. (1989). Conditional discrimination in mentally retarded adults: The effect of training the component simple discriminations. Journal of the Experimental Analysis of Behavior, 52, 1-12.

Savage-Rumbaugh, E. S., Rumbaugh, D. M., Smith, S. T., \& Lawson, J. (1980). Reference: The linguistic essential. Science, 210, 922925.

Schusterman, R. J., \& Kastak, D. (1993). A California sea lion (Zalophus californianus) is capable of forming equivalence relations. Psychological Record, 43, 823-839.

Sidman, M. (1990). Equivalence relations: Where do they come from? In D. E. Blackman \& H. Lejeune (Eds.), Behavior analysis in theory and practice: Contributions and controversies (pp. 93-114). Hillsdale, NJ: Erlbaum.

Sidman, M. (1994). Equivalence relations and behavior: A research story. Boston: Authors Cooperative.

Sidman, M. (2000). Equivalence relations and the reinforcement contingency. Journal of the Experimental Analysis of Behavior, 74, 127-146.

Sidman, M., Cresson, O., Jr., \& Willson-Morris, M. (1974). Acquisition of matching to sample via mediated transfer. Journal of the Experimental Analysis of Behavior, 22, 261-273.

Sidman, M., Rauzin, R., Lazar, R., Cunningham, S., Tailby, W., \& CARRIGAN, P. (1982). A search for symmetry in the conditional discriminations of rhesus monkeys, baboons, and children. Journal of the Experimental Analysis of Behavior, 37, 23-44.

Sidman, M., \& Tailby, W. (1982). Conditional discrimination vs. matching to sample: An expansion of the testing paradigm. Journal of the Experimental Analysis of Behavior, 37, 5-22.

Siegel, S., \& Domjan, M. (1971). Backward conditioning as an inhibitory procedure. Learning \& Motivation, 2, 1-11.

Spetch, M. L., Wilkie, D. M., \& Pinel, J. P. J. (1981). Backward conditioning: A reevaluation of the empirical evidence. Psychological Bulletin, 89, 163-175.

Spradlin, J. E., Cotter, V. W., \& Baxley, N. (1973). Establishing a conditional discrimination without direct training: A study of transfer with retarded adolescents. American Journal of Mental Deficiency, 77, 556-566. 
StodDard, L. T., \& Sidman, M. (1971). The removal and restoration of stimulus control. Journal of the Experimental Analysis of Behavior, 16, 143-154.

Stromer, R., \& Osborne, J. G. (1982). Control of adolescents' arbitrary matching-to-sample by positive and negative stimulus relations. Journal of the Experimental Analysis of Behavior, 37, 329-348.

Tait, R. W., \& Saladin, M. E. (1986). Concurrent development of excitatory and inhibitory associations during backward conditioning. Learning \& Behavior, 14, 133-137.

Tedford, W. H., JR., \& HAZEL, J. S. (1973). Stimulus location as a factor in associative symmetry. Journal of Experimental Psychology, 101, 189-190.

Tomonaga, M., Matsuzawa, T., Fujita, K., \& Yamamoto, J. (1991). Emergence of symmetry in a visual conditional discrimination by chimpanzees (Pan troglodytes). Psychological Reports, 68, 51-60.

UrCuioli, P. J. (2008). Associative symmetry, antisymmetry, and a theory of pigeons' equivalence-class formation. Journal of the Experimental Analysis of Behavior, 90, 257-282.

Urcuioli, P. J., \& DeMarse, T. B. (1997). Further tests of responseoutcome associations in differential-outcome matching-to-sample. Journal of Experimental Psychology: Animal Behavior Processes, 23, 171-182.

Urcuioli, P. J., \& Honig, W. K. (1980). Control of choice in conditional discriminations by sample-specific behaviors. Journal of Experimental Psychology: Animal Behavior Processes, 6, 251-277.

Urcuioli, P. J., MichaleK, S., \& Lionello-DeNolf, K. M. (2006, No- vember). The continuing search for symmetry in pigeons. Presented at the 47th Annual Meeting of the Psychonomic Society, Houston.

VAUGHAN, W. (1988). Formation of equivalence sets in pigeons. Journal of Experimental Psychology: Animal Behavior Processes, 14, 36-42.

Wagner, A. R., \& Terry, W. S. (1975). Backward conditioning to a CS following an expected vs. a surprising UCS. Animal Learning \& Behavior, 3, 370-374.

Weinstein, B. (1945). The evolution of intelligent behavior in rhesus monkeys. Genetic Psychology Monographs, 31, 3-48.

Wollen, K. A., Fox, R. A., \& Lowry, D. H. (1970). Variations in asymmetry as a function of degree of forward learning. Journal of Verbal Learning \& Verbal Behavior, 86, 416-419.

Yamamoto, J., \& Asano, T. (1995). Stimulus equivalence in a chimpanzee (Pan troglodytes). Psychological Record, 45, 3-21.

Zentall, T. R., Edwards, C. A., Moore, B. S., \& Hogan, D. E. (1981). Identity: The basis for both matching and oddity learning in pigeons. Journal of Experimental Psychology: Animal Behavior Processes, 7, 70-86.

Zentall, T. R., Sherburne, L. M., \& Steirn, J. N. (1992). Development of excitatory backward associations during the establishment of forward associations in a delayed conditional discrimination by pigeons. Learning \& Behavior, 20, 199-206.

(Manuscript received February 29, 2008;

revision accepted for publication October 25, 2008.) 